\title{
Crown to Rump Length Measurement
}

National Cancer Institute

\section{Source}

National Cancer Institute. Crown to Rump Length Measurement. NCI Thesaurus. Code C81242.

A measurement from the high prominence of the head to the low prominence of the buttocks of a fetus or embryo during ultrasound. This measurement is useful in determining gestational age. 